\title{
Promotion of $\mathrm{Ni}^{2+}$ Removal by Masking Toxicity to Sulfate-Reducing Bacteria: Addition of Citrate
}

\section{Junwei Qian ${ }^{1, \dagger}$, Xiaoyu Zhu ${ }^{1, \dagger}$, Yong Tao ${ }^{1, *}$, Yan Zhou ${ }^{2}$, Xiaohong He ${ }^{1}$ and Daping Li ${ }^{1, *}$}

1 Key Laboratory of Environmental and Applied Microbiology, Chengdu Institute of Biology, Chinese Academy of Sciences \& Environmental Microbiology Key Laboratory of Sichuan Province, Chengdu 610041, China; E-Mails: jwqian209@outlook.com (J.Q.); zhuxy@cib.ac.cn (X.Z.); hexh@cib.ac.cn (X.H.)

2 College of Life Science, Sichuan University, Chengdu 610064, China; E-Mail: zhyn807@163.com

$\dagger$ These authors contributed equally to this work.

* Authors to whom correspondence should be addressed;

E-Mails: taoyong@cib.ac.cn (Y.T.); lidp@cib.ac.cn (D.L.);

Tel.: +86-28-8289-0211 (Y.T. \& D.L.); Fax: +86-28-8289-0288 (Y.T. \& D.L.).

Academic Editor: Ji-Dong Gu

Received: 21 November 2014 / Accepted: 3 April 2015 / Published: 9 April 2015

\begin{abstract}
The sulfate-reducing bioprocess is a promising technology for the treatment of heavy metal-containing wastewater. This work was conducted to investigate the possibility of promoting heavy metal removal by the addition of citrate to mask $\mathrm{Ni}^{2+}$ toxicity to sulfate-reducing bacteria (SRB) in batch reactors. SRB growth was completely inhibited in $\mathrm{Ni}^{2+}$-containing medium $(1 \mathrm{mM})$ when lactate served as the sole carbon resource, leading to no sulfate reduction and $\mathrm{Ni}^{2+}$ removal. However, after the addition of citrate, $\mathrm{SRB}$ grew well, and sulfate was quickly reduced to sulfide. Simultaneously, the Ni-citrate complex was biodegraded to $\mathrm{Ni}^{2+}$ and acetate. The $\mathrm{NiS}$ precipitate was then formed, and $\mathrm{Ni}^{2+}$ was completely removed from the solution. It was suggested that the addition of citrate greatly alleviates $\mathrm{Ni}^{2+}$ toxicity to $\mathrm{SRB}$ and improves the removal of $\mathrm{Ni}^{2+}$, which was confirmed by quantitative real-time PCR targeting dissimilatory sulfite reductase (dsrAB) genes. Analysis of the carbon metabolism indicated that lactate instead of acetate served as the electron donor for sulfate reduction. This study offers a potential approach to increase the removal of heavy metals from wastewater in the single stage SRB-based bioprocess.
\end{abstract}


Keywords: Ni removal; Ni-citrate complex; toxicity masking; lactate; sulfate reduction

\section{Introduction}

Heavy metals, often associated with mine waters and industrial wastewater contributions, have been reported as a cause of many human diseases, such as kidney or nervous system damages and cancers. Sulfate-reducing bioprocess for treating wastewaters from mining and mineral processing are becoming an alternative to conventional chemical treatment [1-3]. This anaerobic process is carried out by sulfate-reducing bacteria (SRB) that utilize sulfate as the final electron acceptor for the oxidation of organic compounds (electron donors), resulting in the production of hydrogen sulfide $\left(\mathrm{H}_{2} \mathrm{~S}\right)$. The removal of metals by SRB is mainly due to the production of highly insoluble precipitates with the biologically produced $\mathrm{H}_{2} \mathrm{~S}$, as shown in Equations (1) and (2) [4]:

$$
2 \mathrm{CH}_{2} \mathrm{O}+\mathrm{SO}_{4}^{2-} \rightarrow \mathrm{H}_{2} \mathrm{~S}+2 \mathrm{HCO}_{3}^{-}
$$

where $\mathrm{CH}_{2} \mathrm{O}=$ Electron donor;

$$
\mathrm{H}_{2} \mathrm{~S}+\mathrm{M}^{2+} \rightarrow \mathrm{MS}(\mathrm{s})+2 \mathrm{H}^{+}
$$

where $\mathrm{M}^{2+}=$ Metal, such as $\mathrm{Ni}^{2+}$.

In comparison with traditional chemical treatment, the sulfate-reducing bioprocess could combine the removal of soluble metals and sulfate with low sludge production and cost effectiveness [5].

In recent years, the SRB-based bioprocess has been successfully applied by using single or separated unit processes to treat metal-containing wastewaters [4-6]. In the single-stage process, biological sulfide production and chemical metal sulfide precipitation occur simultaneously in the same reactor, whereas in the two-stage configuration, these steps take place separately in different reactors [7]. In comparison with the separated unit process, the single-stage process has the advantage of low capital investment and operational costs [5]. However, the single-stage process may not be viable if the wastewater contains relatively high concentration of heavy metals. In anaerobic semi-continuous stirred tank reactors, when the heavy metal concentration is above the tolerable concentration of SRB, the growth and sulfate-reducing activity of SRB were completely inhibited, and no metal was removed from the solutions [8].

Citric acid is a naturally occurring hydroxycarboxylic acid. Under anaerobic condition, citrate was fermented to formate and acetate, and the produced acetate served as the electron donor for sulfate reduction $[9,10]$. Citrate is also a multidentate chelating agent, which forms stable metal-citrate complexes with heavy metals [11]. It was reported that citrate effectively masked $\mathrm{Ni}^{2+}$ toxicity to Pseudomonas fluorescens and P. alcaliphila via the formation of non-toxic Ni-citrate complex, and bidentate Ni-citrate complex was biodegraded into $\mathrm{Ni}^{2+}$ and $\mathrm{CO}_{2}$ under aerobic conditions [12-14]. To date, research relating to masking Ni toxicity to SRB via citrate complexation in a single-stage SRB-based process has never been reported.

The aims of this work are to investigate: (i) Whether the addition of citrate can alleviate $\mathrm{Ni}^{2+}$ toxicity to $\mathrm{SRB}$; (ii) The promotion of $\mathrm{Ni}^{2+}$ removal by masking toxicity to $\mathrm{SRB}$; and (iii) The mechanism of $\mathrm{Ni}^{2+}$ masking and removal. 


\section{Results}

\subsection{The Effect of the Addition of Citrate on $\mathrm{Ni}^{2+}$ Toxicity}

Table 1 shows $\mathrm{Ni}$ speciation present in initial $\mathrm{Ni} /$ citrate $(0), \mathrm{Ni} /$ citrate $(0.5)$ and $\mathrm{Ni} /$ citrate $(1.0)$ media after the addition of SRB culture. In the absence of citrate, Ni was present predominantly in the forms of the Ni-lactate complex (43.21\%) and free $\mathrm{Ni}^{2+}(26.20 \%)$. In the $\mathrm{Ni} /$ citrate $(0.5)$ and $\mathrm{Ni} /$ citrate (1.0) media, the predominant $\mathrm{Ni}$-citrate complex constituted $45.58 \%$ and $74.92 \%$ and the Ni-lactate complex constituted $23.10 \%$ and $8.02 \%$, respectively. These results indicated that the presence of citrate led to a great reduction of free $\mathrm{Ni}^{2+}$. Figure 1 shows the variation of $\mathrm{OD}_{660}$ values and final $\mathrm{SRB}$ concentration in the four different treatments. In the absence of $\mathrm{Ni}$, after a lag period of 0.5 day, the $\mathrm{OD}_{660}$ of the $\mathrm{Ni}$-free control media increased rapidly and reached a maximum value within 4 days, and the final SRB concentration increased from $3.71 \times 10^{7}$ cells $/ \mathrm{mL}$ (initial SRB concentration in each treatment) to $1.65 \times 10^{9}$ cells $/ \mathrm{mL}$. In the presence of $1 \mathrm{mM} \mathrm{Ni}$ without citrate, both OD 660 and the final SRB concentration maintained the initial level with little change during the experiments. In the $\mathrm{Ni} /$ citrate $(0.5)$ and $\mathrm{Ni} /$ citrate (1.0) media, $\mathrm{OD}_{660}$ reached to 0.12 and 0.14 within 4 day, respectively, over 20-times higher than the initial level. Meanwhile, the final SRB concentration increased greatly to $1.38 \times 10^{9}$ and $1.92 \times 10^{9}$ cells $/ \mathrm{mL}$, respectively. The above results showed that the biomass of the mixed culture and SRB increases significantly after the addition of citrate, suggesting that citrate can effectively alleviate Ni toxicity for all anaerobic bacteria, including SRB.

Table 1. Predicted nickel speciation in $\mathrm{Ni} /$ citrate $(0), \mathrm{Ni} /$ citrate $(0.5)$ and $\mathrm{Ni} /$ citrate $(1.0)$ media using the MINTEQ 3.0 model.

\begin{tabular}{|c|c|c|c|c|c|c|c|c|}
\hline \multirow{2}{*}{ Media } & \multicolumn{8}{|c|}{ \% of Total Ni (1 mM) } \\
\hline & $\mathrm{Ni}^{2+}$ & $\mathrm{NiCl}^{+}$ & $\mathrm{NiSO}_{4}$ (aq) & {$[\mathrm{Ni}-\text { Lactate }]^{+}$} & 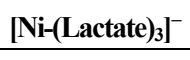 & Ni-(Lactate) $)_{2}$ (aq) & [Ni-Citrate $^{-}$ & {$\left[\mathrm{Ni}-(\text { Citrate })_{2}\right]^{4-}$} \\
\hline $\mathrm{Ni} /$ citrate $(0)$ & 26.20 & 0.03 & 16.18 & 43.21 & 0.714 & 13.67 & - & - \\
\hline $\mathrm{Ni} /$ citrate $(0.5)$ & 13.88 & 0.01 & 8.53 & 23.10 & 0.39 & 7.38 & 45.58 & 0.84 \\
\hline $\mathrm{Ni} /$ citrate $(1.0)$ & 4.79 & - & 2.92 & 8.02 & 0.14 & 2.58 & 74.92 & 6.63 \\
\hline
\end{tabular}

(a)

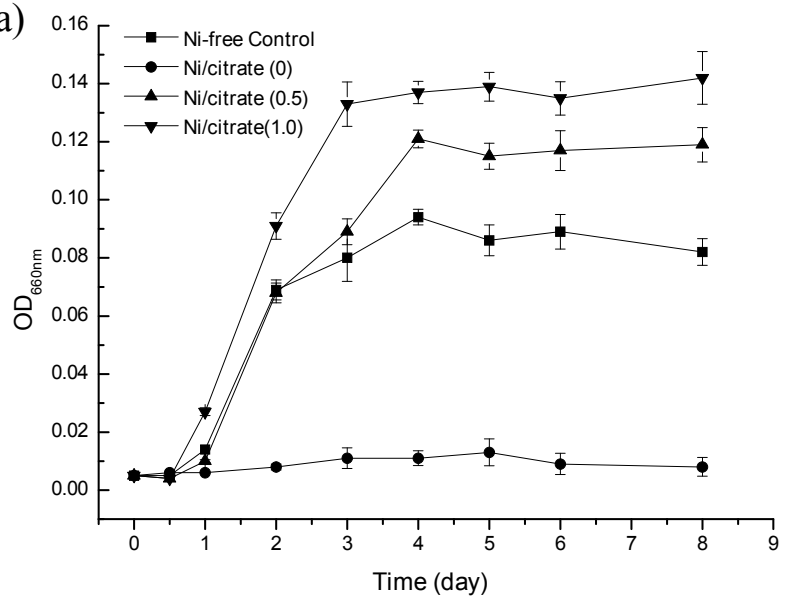

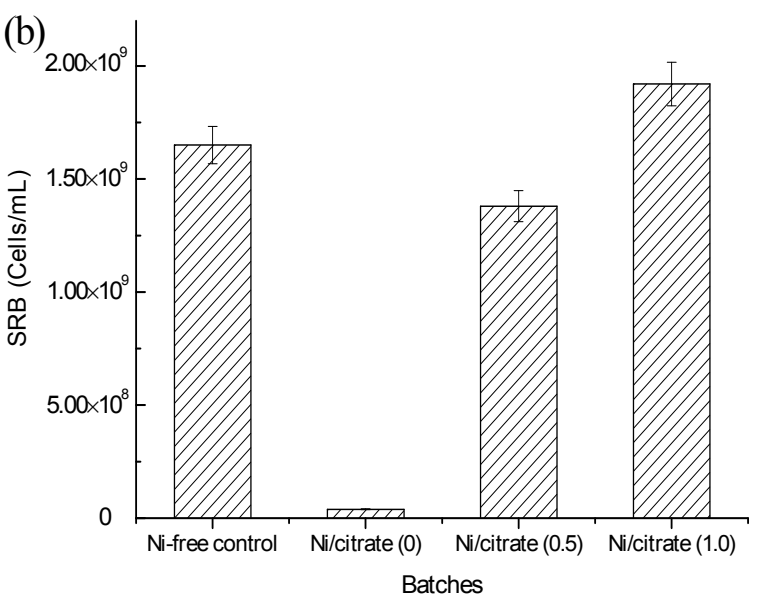

Figure 1. Variations of $\mathrm{OD}_{660}$ (a) and final sulfate-reducing bacteria (SRB) (b) in Ni-free control, $\mathrm{Ni} /$ citrate $(0), \mathrm{Ni} /$ citrate $(0.5)$ and $\mathrm{Ni} /$ citrate $(1.0)$ media (error bars represent one standard deviation of the mean; $n=3)$. 
Table 2 shows the final concentrations of the sulfate, dissolved sulfide, $\mathrm{Ni}$, as well as final $\mathrm{pH}$ values in the four treatments. At the end of incubation, in the Ni-free control, $\mathrm{Ni} /$ citrate $(0.5)$ and $\mathrm{Ni} /$ citrate (1.0) media, sulfate concentration decreased from 30.00 to $25.08,24.26$ and $24.00 \mathrm{mM}$, respectively. The $\mathrm{pH}$ values increased to 7.09, 7.23 and 7.18, respectively, except the $\mathrm{Ni}$ /citrate (0) media, the $\mathrm{pH}$ value of which remained at 6.77. No variation of sulfate and $\mathrm{Ni}$ was observed in $\mathrm{Ni} /$ citrate $(0)$ media during the whole period of the experiment. At the end of the incubation, the black precipitate appeared at the bottom of the reactors containing the $\mathrm{Ni} /$ citrate $(0.5)$ and $\mathrm{Ni} /$ citrate (1.0) media, and it was completely removed from the solutions. Energy dispersive X-ray spectroscopy (EDS) results demonstrated that the black precipitate was mostly composed of sulfur and nickel with a metal/sulfur ratio of 1.0 (Figure 2a). X-ray diffraction (XRD) analysis further confirmed that the metal crystals were NiS (Figure 2b).

Table 2. Final concentrations of sulfate, sulfide and $\mathrm{Ni}$, as well as final $\mathrm{pH}$ values in the Ni-free control, Ni/citrate (0), Ni/citrate (0.5) and Ni/citrate (1.0) media.

\begin{tabular}{ccccc}
\hline Media & $\mathbf{p H}$ & Sulfate $(\mathbf{m M})$ & Sulfide $(\mathbf{m M})$ & Ni $(\mathbf{m M})$ \\
\hline Ni-free control & $7.09 \pm 0.31$ & $25.08 \pm 1.57$ & $1.44 \pm 0.04$ & - \\
Ni/citrate (0) & $6.77 \pm 0.23$ & $29.96 \pm 1.46$ & $0.08 \pm 0.01$ & $0.98 \pm 0.04$ \\
Ni/citrate $(0.5)$ & $7.23 \pm 0.18$ & $24.26 \pm 1.26$ & $1.50 \pm 0.03$ & 0 \\
Ni/citrate (1.0) & $7.18 \pm 0.15$ & $24.00 \pm 1.31$ & $1.63 \pm 0.05$ & 0 \\
\hline
\end{tabular}

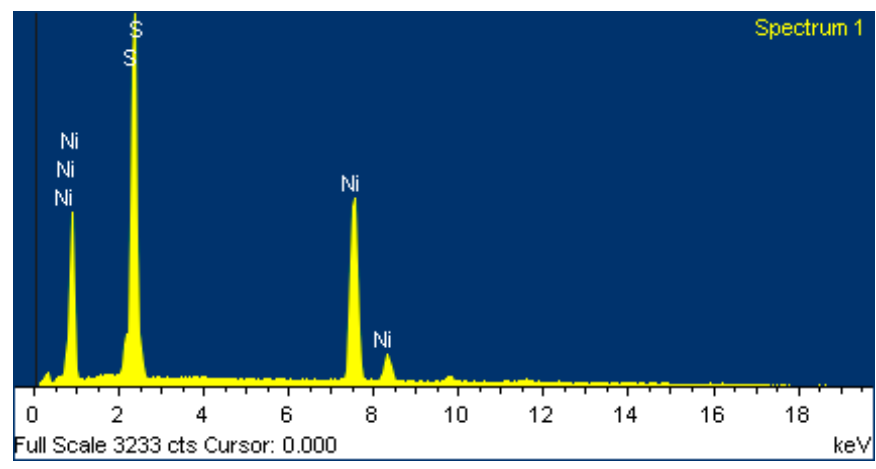

(a)

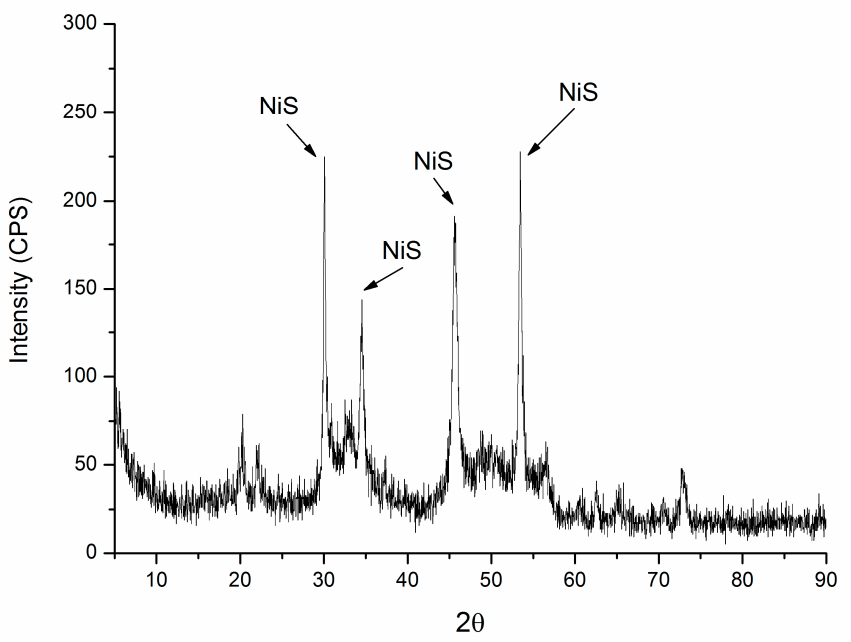

(b)

Figure 2. Energy dispersive X-ray spectroscopy (EDS) (a) and X-ray diffraction (XRD) (b) analysis of the precipitate. 


\subsection{Mechanism of $\mathrm{Ni}^{2+}$ Masking and Removal}

Figure 3 shows the variations of sulfate, sulfide, lactate and acetate concentration in the citrate/ Ni-free lactate medium. The sulfate concentration decreased to $25.08 \mathrm{mM}$ at the rate of $0.98 \mathrm{mmol} / \mathrm{L} \cdot$ day within five days, while the dissolved sulfide concentration increased to $1.44 \mathrm{mM}$ (Figure $3 \mathrm{a}$ ). At the same time, lactate was completely consumed, and the acetate concentration increased to $15 \mathrm{mM}$ (Figure $3 \mathrm{~b}$ ). Acetate was the main metabolic product from lactate in the $\mathrm{Ni} /$ citrate-free lactate medium. The simultaneous decline of sulfate and lactate suggested that lactate served as the electron donor for sulfate reduction (Equation (3)) [15].

$$
2 \text { Lactate }+\mathrm{SO}_{4}^{2-} \rightarrow 2 \text { Acetate }+\mathrm{HS}^{-}+2 \mathrm{H}^{+}+2 \mathrm{HCO}_{3}^{-}
$$
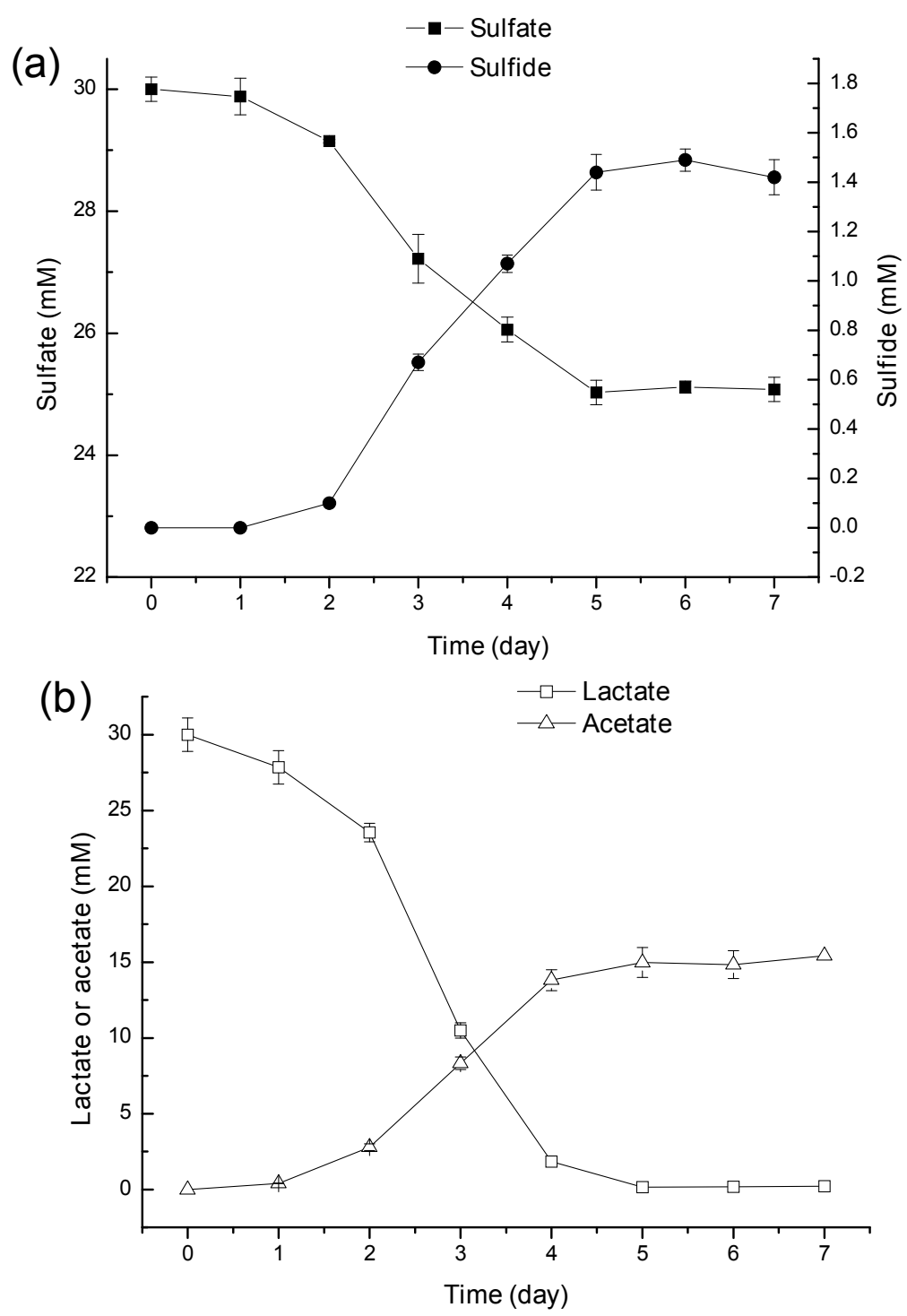

Figure 3. Residual concentrations of sulfate and sulfide (a) and lactate and acetate (b) in Ni-free lactate media with time (error bars represent one standard deviation of the mean; $n=3$ ).

Figure 4 showed that in the lactate-free $\mathrm{Ni} /$ citrate medium, all sulfate still remained in the media during the experiments, and dissolved sulfide was not detected, indicating that sulfate reduction does not occur without lactate as the electron donor. Therefore, Ni was not removed from the solution 
(Figure 4a). Whereas citrate was completely consumed within 2 days, the acetate concentration increased to $2.25 \mathrm{mM}$ and remained relatively constant till the end of the experiments (Figure 4b), demonstrating that citrate and acetate do not serve as electron donors of sulfate reduction in this bioprocess.
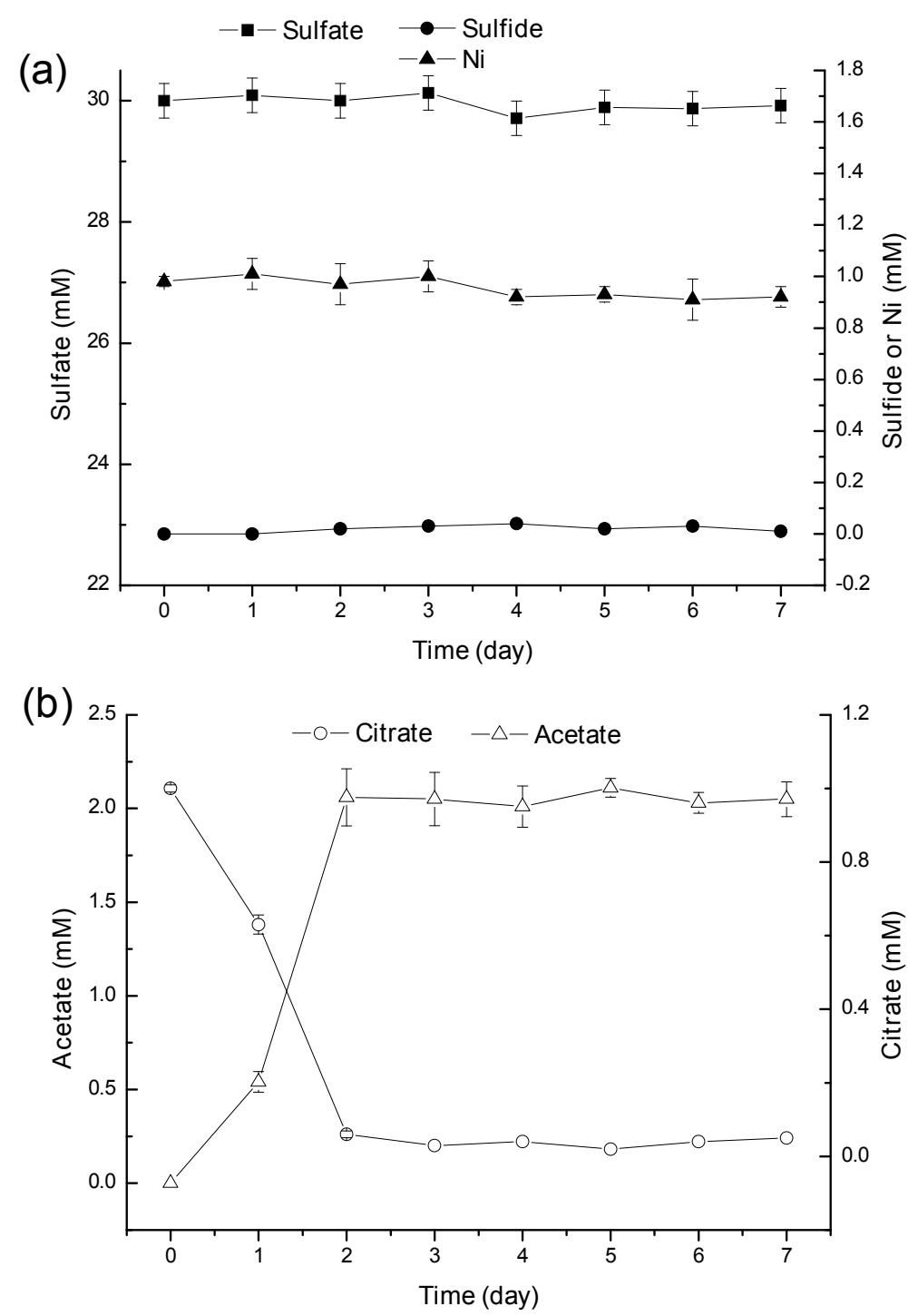

Figure 4. Residual concentrations of sulfate, sulfide and $\mathrm{Ni}$ (a) and citrate and acetate (b) in lactate-free $\mathrm{Ni} /$ citrate media with time (error bars represent one standard deviation of the mean; $n=3)$.

Figure 5 shows that in the lactate-citrate/Ni medium, the sulfate concentration decreased to $24.09 \mathrm{mM}$ within 5 days at the rate of $1.2 \mathrm{mmol} / \mathrm{L} \cdot$ day (Figure 5a). Meanwhile, Ni was completely removed from solutions within 3 days, and a black precipitate was observed at the bottom of the reactor. After the complete removal of $\mathrm{Ni}$, the dissolved sulfide level increased to $1.65 \mathrm{mM}$ within the following two days and remained constant to the end of the experiments (Figure 5a). Without lag periods, lactate and citrate were completely consumed within five and two days at the rate of 6.0 and $0.5 \mathrm{mmol} / \mathrm{L} \cdot$ day, respectively (Figure $5 \mathrm{~b}$ ). Acetate concentration increased to $21.59 \mathrm{mM}$ at the end of the incubation (Figure $5 \mathrm{~b}$ ). 

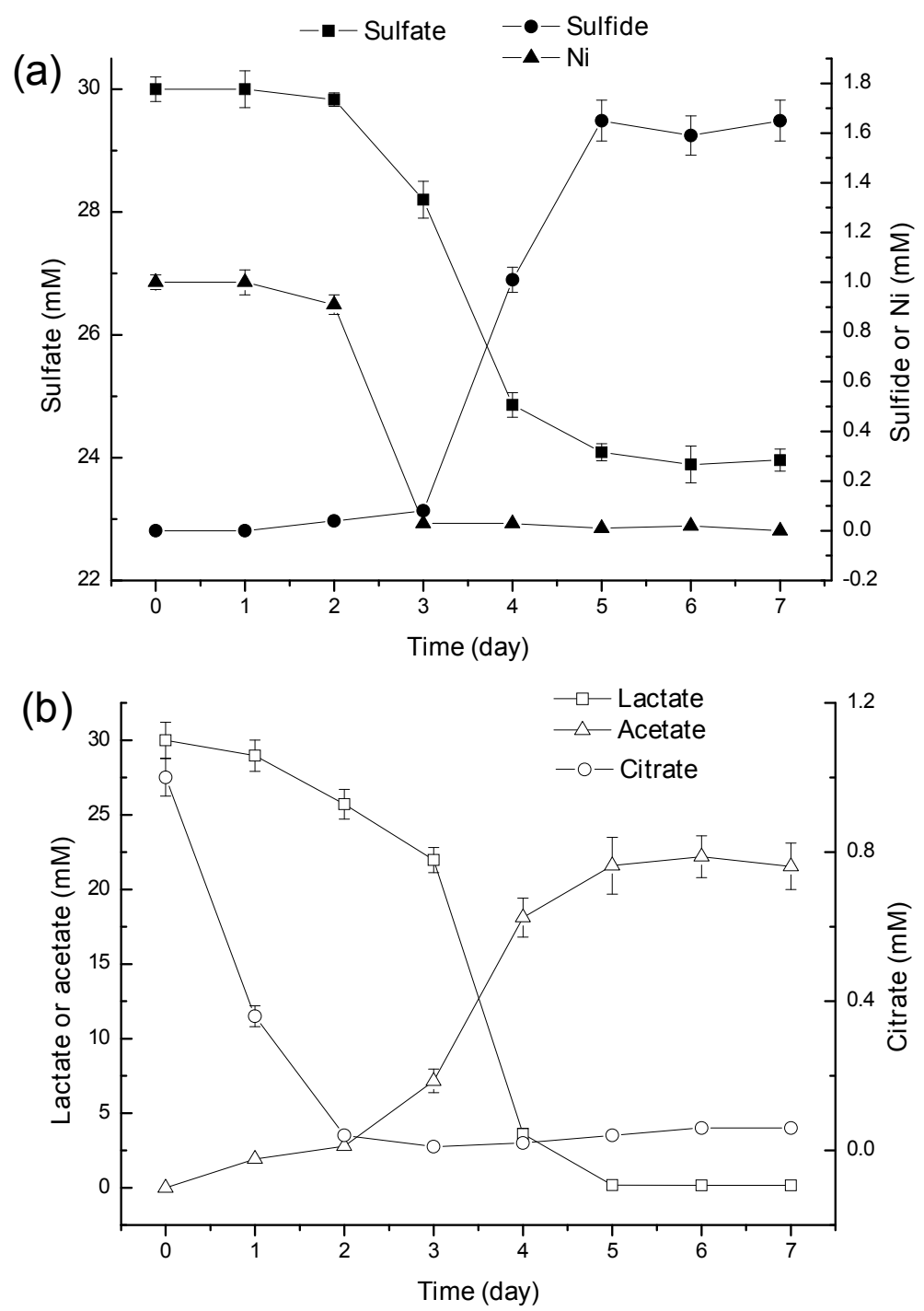

Figure 5. Residual concentrations of sulfate, sulfide and $\mathrm{Ni}$ (a) and lactate, citrate and acetate $(\mathbf{b})$ in the lactate-Ni/citrate media with time (error bars represent one standard deviation of the mean; $n=3$ ).

\subsection{Discussion}

The bioavailability of heavy metal is critically dependent on its speciation, and it is generally assumed that free metal ions are most toxic to microorganisms $[16,17]$. It was reported that $\mathrm{Ni}$ was not toxic to P. fluorescens and P. alcaliphila when it was complexed with citrate $[12,13]$. According to the data obtained from MINTEQ3.0, Ni-citrate and Ni-lactate complexes, free $\mathrm{Ni}^{2+}, \mathrm{NiSO}_{4}$ (aq) and $\mathrm{NiCl}^{+}$were present in the $\mathrm{Ni} /$ citrate (zero), $\mathrm{Ni} /$ citrate $(0.5)$ and $\mathrm{Ni} /$ citrate $(1.0)$ media, but it is unknown whether Ni-lactate complexes $\mathrm{NiSO}_{4}$ (aq) and $\mathrm{NiCl}^{+}$had adverse effects for $\mathrm{SRB}$ growth. Compared with that in the $\mathrm{Ni} /$ citrate $(0)$ media, the concentration of free $\mathrm{Ni}^{2+}$ in the $\mathrm{Ni} /$ citrate $(0.5)$ and $\mathrm{Ni} /$ citrate (1.0) media decreased greatly due to the formation of Ni-citrate complexes. The toxic concentration of $\mathrm{Ni}^{2+}$ for $\mathrm{SRB}$ consortium in the batch test was $20 \mathrm{mg} / \mathrm{L}$ [18], but Poulson et al. found that a $\mathrm{Ni}^{2+}$ concentration greater than $10 \mathrm{mg} / \mathrm{L}$ exerted a marked toxic effect to Desulfovibrio desulfuricans [19]. It was noted in this study that free $\mathrm{Ni}^{2+}$ concentration in the $\mathrm{Ni} /$ citrate $(0.5)$ and $\mathrm{Ni} /$ citrate $(1.0)$ media was lower than the 
previously reported toxic concentration $(20 \mathrm{mg} / \mathrm{L})$. This might be due to the formation of a stable $\mathrm{Ni}$-citrate complex, resulting in the decline of the free $\mathrm{Ni}^{2+}$ in solutions, alleviating the inhibition of $\mathrm{Ni}^{2+}$ on SRB growth. This result was consistent with that of Jong et al. [20] and Kieu et al. [8], who investigated the removal of heavy metals by SRB in semi-continuous stirred tank and bench-scale upflow anaerobic packed bed reactors and found that heavy metal toxicity for SRB might be alleviated via citrate complexation. It should also be noted that the initial free $\mathrm{Ni}^{2+}$ concentration in $\mathrm{Ni} /$ citrate $(0.5)$ medium (about $0.14 \mathrm{mM}$ ) was relatively higher than that in $\mathrm{Ni} /$ citrate $(1.0)$ medium $(0.05 \mathrm{mM})$; whereas there was no significant difference in bacterial growth and the final SRB concentration between the two treatments. This may be attributed to the resistance of SRB itself to $0.14 \mathrm{mM} \mathrm{Ni}^{2+}$ in the $\mathrm{Ni} /$ citrate $(0.5)$ media.

In our study, the precipitate was composed of NiS only; Metal hydroxides or carbonates crystalline phases were not found. The possibility of Ni removal by hydroxide precipitation from a $\mathrm{pH}$ increase and carbonate precipitation from an alkalinity increase can be eliminated. In the $\mathrm{Ni} /$ citrate $(0)$ media, bacterial growth and metabolism were completely inhibited, and the solution $\mathrm{pH}$ remained unchanged. In the $\mathrm{Ni}$-free control, $\mathrm{Ni}$ /citrate $(0.5)$ and $\mathrm{Ni}$ /citrate $(1.0)$ media, the $\mathrm{pH}$ increase may be caused by the alkalinity increase from microbial metabolism [21]. Moreover, it can also be noted that the sulfate reduction efficiencies in the $\mathrm{Ni}$ /citrate $(0.5)(19 \%)$ and $\mathrm{Ni} /$ citrate $(1.0)(20 \%)$ media were both relatively higher than that in Ni-free control media (16.4\%). This may be attributed to the bacterial citrate metabolism from the $\mathrm{Ni}$-citrate complex.

In the range from $\mathrm{pH} 5$ to $\mathrm{pH} 8, \mathrm{Ni}$ and citrate are generally present as a mononuclear bidentate $[\mathrm{NiCit}]^{-}$complex, which could be biodegraded by bacteria under aerobic conditions $[12,13]$. According to MINTEQ3.0, 99.5\% of the $1 \mathrm{mM} \mathrm{Ni}$ was present in the form of the bidentate Ni-citrate complex in the lactate-free $\mathrm{Ni} /$ citrate medium. Citrate consumption suggested that the Ni-citrate complex can be biodegraded under anaerobic conditions, and acetate was the sole metabolic product from the Ni-citrate complex (Equation (4)) [9]. In our study, although bacteria could grow utilizing citrate as a carbon source, acetate could not serve as the electron donor for sulfate reduction, which was different from that reported by Gamez and Stams $[9,10]$.

$$
[\mathrm{Ni} \text { - citrate }]^{-} \rightarrow \mathrm{Ni}^{2+}+2 \text { Acetate }+\mathrm{H}_{2}+2 \mathrm{CO}_{2}
$$

In the lactate-citrate/Ni media, acetate was the sole metabolism product from lactate and citrate, and $\mathrm{Ni}$ was completely removed from the solutions. The simultaneous decrease of sulfate and $\mathrm{Ni}$ concentrations suggested that $\mathrm{Ni}$ was mainly removed via precipitation with the produced sulfide. It was noteworthy that not until complete removal of $\mathrm{Ni}$ did the accumulation of sulfide commenced, and the accumulation of sulfide ceased after the complete consumption of lactate. This suggested that oxidation of lactate to acetate serving as the electron donor may be responsible for the sulfate reduction.

Acetate is a widely-used electron donor for sulfate reduction [2,22]. However, this work suggested that acetate did not serve as the electron donor for sulfate reduction in our treatments, which could be due to the inhibition of acetate-consuming bacteria, either by sulfide or by acetate [23], or by $\mathrm{Ni}^{2+}$ ions in the reactors; whereas the lactate-utilizing SRB was not inhibited. 


\section{Materials and Methods}

\subsection{Sulfate-Reducing Bacteria (SRB) Enrichment}

A mixed culture of SRB using lactate as a carbon source was enriched from the anaerobic sludge collected from a wastewater treatment plant in Chengdu, China. The enrichment medium containing $1.0 \mathrm{~g} / \mathrm{L}$ of sulfate ions had the following composition in $1 \mathrm{~L}$ of deionized water: $1.12 \mathrm{~g}$ glycerol 2-phosphate, $1 \mathrm{~g} \mathrm{NH}_{4} \mathrm{Cl}, 0.85 \mathrm{~g} \mathrm{MgSO}_{4} \cdot 7 \mathrm{H}_{2} \mathrm{O}, 1 \mathrm{~g} \mathrm{Na} 2 \mathrm{SO}_{4}, 0.1 \mathrm{~g}$ yeast, $3.2 \mathrm{~g}$ bromo-ethane-sulfonic-acid (BESA) and $3.2 \mathrm{~g}$ sodium lactate. Magnesium sulfate and sodium sulfate were used as sulfate sources, and glycerol 2-phosphate was used to provide phosphate for cell synthesis. BESA was added to the culture to inhibit methanogenic activity [24]. In brief, $5 \mathrm{~g}$ of anaerobic sludge were inoculated into $100 \mathrm{~mL}$ of the enrichment medium and incubated anaerobically on a rotary shaker $(120 \mathrm{rpm})$ at $30{ }^{\circ} \mathrm{C}$. The sulfate reduction was measured via the analysis of sulfate and sulfide. When the dissolved sulfide concentration increased to $50 \mathrm{mg} / \mathrm{L}, 10 \mathrm{~mL}$ of the culture were transferred into fresh enrichment medium for further enrichment. After 8 continuous transfers, the mixed culture of SRB was obtained by centrifugation $(2500 \times \mathrm{g}, 10 \mathrm{~min})$ and washed 2-3 times with a 20-fold dilution of the enrichment medium. The SRB culture was kept at $4{ }^{\circ} \mathrm{C}$ as the inoculum for further studies.

\subsection{Batch Experiments}

Batch experiments were carried out in serum bottles $(500 \mathrm{~mL})$ containing $450 \mathrm{~mL}$ of the defined mineral medium. The bottles were sparged with $\mathrm{N}_{2}$ for $15 \mathrm{~min}$ to provide a reducing atmosphere. All bottles were sealed with rubber stoppers and aluminum crimps after the addition of $50 \mathrm{~mL}$ of SRB inoculum having $0.5 \mathrm{OD}_{660}$ and were incubated at $30^{\circ} \mathrm{C}$ under shaking at $100 \mathrm{rpm}$.

\subsection{Defined Mineral Media}

All media contained the sulfate medium (g/L): Glycerol 2-phosphate, 0.3; $\mathrm{NH}_{4} \mathrm{Cl}, 0.3 ; \mathrm{Na}_{2} \mathrm{SO}_{4}, 4.26$; yeast, $0.05 ; \mathrm{MgCl}_{2}, 0.05 ; \mathrm{BESA}, 3.2 . \mathrm{NiCl}_{2} \cdot 6 \mathrm{H}_{2} \mathrm{O}$ was used as the source of $\mathrm{Ni}$, and lactate and citrate were added in the form of sodium lactate and sodium citrate. The addition amounts of $\mathrm{Ni}$, lactate and citrate in defined mineral media were calculated according to the experiment demands. Solution $\mathrm{pH}$ was adjusted to 6.8 with $\mathrm{HCl}$ or $\mathrm{NaOH}$.

\subsection{Effect of Citrate on the SRB Growth and $\mathrm{Ni}^{2+}$ Removal}

For the toxicity masking experiments, the four treatments were as follows: (1) Ni-free control: $30 \mathrm{mM}$ lactate; (2) Ni/citrate (0): $30 \mathrm{mM}$ lactate $+1.0 \mathrm{mM} \mathrm{Ni}^{2+}$; (3) Ni/citrate (0.5): $30 \mathrm{mM}$ lactate $+0.5 \mathrm{mM}$ citrate $+1 \mathrm{mM} \mathrm{Ni}^{2+}$; (4) Ni/citrate $(1.0): 30 \mathrm{mM}$ lactate $+1.0 \mathrm{mM}$ citrate $+1.0 \mathrm{mM}$ $\mathrm{Ni}^{2+}$. Speciation of $\mathrm{Ni}$ in $\mathrm{Ni} /$ citrate $(0), \mathrm{Ni} /$ citrate $(0.5)$ and $\mathrm{Ni} /$ citrate $(1.0)$ was verified using the MINTEQ3.0 program. Glycerol 2-phosphate and bromo-ethane-sulfonic-acid were not found in the database and were not included. Thermodynamic constants in the MINTEQ3.0 database were used in the calculations. Samples were withdrawn periodically for analysis of $\mathrm{OD}_{660}$ to monitor bacterial growth. At the end of the experiment, samples were taken for analysis of nickel, sulfate, sulfide, as well as quantification analysis of SRB. Each treatment had three replicates. 


\subsection{Biodegradation of Ni-Citrate Complex}

Three treatments were conducted as follows: (1) Citrate/Ni-free lactate medium: $30 \mathrm{mM}$ lactate; (2) Lactate-free citrate/Ni medium: $1.0 \mathrm{mM}$ citrate $+1.0 \mathrm{mM} \mathrm{Ni}^{2+}$; (3) Lactate-citrate/Ni medium: $30 \mathrm{mM}$ lactate $+1.0 \mathrm{mM}$ citrate $+1.0 \mathrm{mM} \mathrm{Ni}^{2+}$. Samples were withdrawn periodically for the analysis of sulfate, sulfide, Ni and organic acids. Each treatment had three replicates.

\subsection{Analytical Methods}

The microbial population density was determined spectrophotometrically at $660 \mathrm{~nm}$ (TU-1810 UV-Vis Spectrophotometer, Purkinje General Instrument Co., Beijing, China). Sulfate was measured by ion chromatography (Metrohm 761 Compact IC, Metrohm Ltd., Herisau, Switzerland). Sample separation and elution were performed using a Metrosep A Supp 5-150 analytical column (Metrohm Ltd., Herisau, Switzerland) with carbonate/bicarbonate eluent (3.2 $\mathrm{mM} \mathrm{Na}_{2} \mathrm{CO}_{3} / 1.0 \mathrm{mM} \mathrm{NaHCO} 3$ at $0.7 \mathrm{~mL} / \mathrm{min}$ ). Quantitative determination of sulfide was performed calorimetrically by the methylene blue method [25]. Ni was determined by atomic absorption spectrometry (AAS, Z-2300, Hitachi, Japan). Lactate, acetate and citrate were analyzed by HPLC equipped with a Hi-Plex H column and an RID detector set at $45{ }^{\circ} \mathrm{C}$ (Agilent Technologies, Palo Alto, CA, USA). The metal sulfide precipitate was characterized by energy dispersive X-ray spectroscopy (EDS, IE 150, Oxford Instrument, Oxfordshire, UK) and X-ray diffraction (XRD, DX2500, Fangyuan Instrument Co., Ltd., Dandong, China) analysis.

Quantification of SRB was conducted by quantitative real-time PCR (q-PCR). Samples (about $0.02 \mathrm{~g}$ ) from each treatments were washed three times with phosphate-buffered saline and centrifuging each preparation at $14,000 \times g$; Then, DNA was extracted using genomic DNA using the Soil DNA isolation Kit (MO BIO Laboratories, Carlsbad, CA, USA) according to the manufacturer's instructions. The SRBs were quantified by an evaGreen assay targeting the dsrAB genes using a primer set: DSR1-F+ (5'-ACS CAC TGG AAG CAC GGC GG-3') and DSR-R (5'-GTG GMR CCG TGC AKR TTG G-3') (the expected product size is $221 \mathrm{bp}$ ) [26]. The q-PCR amplification was performed in a C1000 touch thermal cycle equipped with a CFX 384 Real-Time system (Biorad, Hercules, CA, USA). Results were expressed as the number of cells per milliliter of culture, assuming that the SRB contained only one copy of $d s r A B$ gene per cell [27].

\section{Conclusions}

These data provide the first evidence of promoting $\mathrm{Ni}$ removal by masking $\mathrm{Ni}^{2+}$ toxicity to $\mathrm{SRB}$ via citrate complexation in batch reactors. In the presence of citrate, $\mathrm{Ni}$-citrate complex formation led to the decline of free $\mathrm{Ni}^{2+}$ in solution, lessening $\mathrm{Ni}$ toxicity for and inhibition of SRB. In the biodegradation process, the Ni-citrate complex was biodegraded to $\mathrm{Ni}^{2+}$ and acetate, and sulfate was reduced to sulfide by $\mathrm{SRB}$ using lactate as the electron donor. The $\mathrm{NiS}$ precipitate was then formed, and $\mathrm{Ni}^{2+}$ was completely removed from the solution. Therefore, when wastewater contains a relatively high concentration of $\mathrm{Ni}^{2+}$, it is feasible to promote $\mathrm{Ni}$ removal by masking $\mathrm{Ni}^{2+}$ toxicity to $\mathrm{SRB}$ via citrate complexation in the single-stage SRB-based bioprocess. This approach offers a potential alternative to increase the removal of other heavy metals from wastewater, such as $\mathrm{Cu}^{2+}, \mathrm{Zn}^{2+}, \mathrm{Pb}^{2+}$, etc. 


\section{Acknowledgments}

This research was sponsored by the National Natural Science Foundation of China (No. 31300106) and the China Postdoctoral Science Foundation (No. 2013M542298).

\section{Author Contributions}

Yong Tao and Daping Li conceived of and designed the experiments; Junwei Qian, Xiaoyu Zhu, Yan Zhou and Xiaohong He performed the experiments; Junwei Qian analyzed the data, and Xiaoyu Zhu and Yong Tao wrote the paper.

\section{Conflicts of Interest}

The authors declare no conflict of interest.

\section{References}

1. Albertson, O.E. Of: Changes in the biochemical oxygen demand procedure in the 21st edition of Standard Methods for the Examination of Water and Wastewater, James C. Young, Lenore S. Clesceri, sabry M. Kamhawy, 77, 404-410 (2005). Water Environ. Res. 2007, 79, 453-455; discussion 455-456.

2. Liamleam, W.; Annachhatre, A.P. Electron donors for biological sulfate reduction. Biotechnol. Adv. 2007, 25, 452-463.

3. Qiu, R.; Zhao, B.; Liu, J.; Huang, X.; Li, Q.; Brewer, E.; Wang, S.; Shi, N. Sulfate reduction and copper precipitation by a Citrobacter sp. isolated from a mining area. J. Hazard. Mater. 2009, 164, 1310-1315.

4. Muyzer, G.; Stams, A.J.M. The ecology and biotechnology of sulphate-reducing bacteria. Nat. Rev. Microbiol. 2008, 6, 441-454.

5. Kaksonen, A.H.; Puhakka, J.A. Sulfate reduction based bioprocesses for the treatment of acid mine drainage and the recovery of metals. Eng. Life Sci. 2007, 7, 541-564.

6. Dvorak, D.H.; Hedin, R.S.; Edenborn, H.M.; Mcintire, P.E. Treatment of metal-contaminated water using bacterial sulfate reduction: Results from pilot-scale reactors. Biotechnol. Bioeng. 1992, 40, 609-616.

7. Gallegos-Garcia, M.; Celis, L.B.; Rangel-Mendez, R.; Razo-Flores, E. Precipitation and recovery of metal sulfides from metal containing acidic wastewater in a sulfidogenic down-flow fluidized bed reactor. Biotechnol. Bioeng. 2009, 102, 91-99.

8. Kieu, H.T.Q.; Muller, E.; Horn, H. Heavy metal removal in anaerobic semi-continuous stirred tank reactors by a consortium of sulfate-reducing bacteria. Water Res. 2011, 45, 3863-3870.

9. Gamez, V.M.; Sierra-Alvarez, R.; Waltz, R.J.; Field, J.A. Anaerobic degradation of citrate under sulfate reducing and methanogenic conditions. Biodegradation 2009, 20, 499-510.

10. Stams, A.J.M.; Huisman, J.; Encina, P.A.G.; Muyzer, G. Citric acid wastewater as electron donor for biological sulfate reduction. Appl. Microbiol. Biotechnol. 2009, 83, 957-963.

11. Dodge, C.J.; Francis, A.J. Photodegradation of a ternary iron(III)-Uranium(VI)-Citric acid complex. Environ. Sci. Technol. 2002, 36, 2094-2100. 
12. Francis, A.J.; JoshiTope, G.A.; Dodge, C.J. Biodegradation of nickel-citrate and modulation of nickel toxicity by iron. Environ. Sci. Technol. 1996, 30, 562-568.

13. Qian, J.; Li, D.; Zhan, G.; Zhang, L.; Su, W.; Gao, P. Simultaneous biodegradation of Ni-citrate complexes and removal of nickel from solutions by Pseudomonas alcaliphila. Bioresour. Technol. 2012, 116, 66-73.

14. Qian, J.W.; Tao, Y.; Zhang, W.J.; He, X.H.; Gao, P.; Li, D.P. Presence of $\mathrm{Fe}^{3+}$ and $\mathrm{Zn}^{2+}$ promoted biotransformation of Cd-citrate complex and removal of metals from solutions. J. Hazard. Mater. 2013, 263 Pt 2, 367-373.

15. Wakeman, K.D.; Erving, L.; Riekkola-Vanhanen, M.L.; Puhakka, J.A. Silage supports sulfate reduction in the treatment of metals- and sulfate-containing waste waters. Water Res. 2010, 44, 4932-4939.

16. Hughes, M.N.; Poole, R.K. Metal speciation and microbial-growth-The hard (and soft) facts. J. Gen. Microbiol. 1991, 137, 725-734.

17. Van Nostrand, J.D.; Sowder, A,G.; Bertsch, P.M.; Morris, P.J. Effect of pH on the toxicity of nickel and other divalent metals to Burkholderia cepacia PR1 ${ }_{301}$. Environ. Toxicol. Chem. 2005, 24, 2742-2750.

18. Hao, S.; Jiao, M.; Zhao, J.; Xing, M.; Huang, B. Reorganization and condensation of chromatin in mitotic prophase nuclei of Allium cepa. Chromosoma 1994, 103, 432-440.

19. Poulson, S.R.; Colberg, P.J.S.; Drever, J.I. Toxicity of heavy metals (Ni, Zn) to Desulfovibrio desulfuricans. Geomicrobiol. J. 1997, 14, 41-49.

20. Jong, T.; Parry, D.L. Removal of sulfate and heavy metals by sulfate reducing bacteria in short-term bench scale upflow anaerobic packed bed reactor runs. Water Res. 2003, 37, 3379-3389.

21. Celis-Garcia, L.B.; Razo-Flores, E.; Monroy, O. Performance of a down-flow fluidized-bed reactor under sulfate reduction conditions using volatile fatty acids as electron donors. Biotechnol. Bioeng. 2007, 97, 771-779.

22. Kaksonen, A.H.; Franzmann, P.D.; Puhakka, J.A. Effects of hydraulic retention time and sulfide toxicity on ethanol and acetate oxidation in sulfate-reducing metal-precipitating fluidized-bed reactor. Biotechnol. Bioeng. 2004, 86, 332-343.

23. Nagpal, S.; Chuichulcherm, S.; Peeva, L.; Livingston, A. Microbial sulfate reduction in a liquid-solid fluidized bed reactor. Biotechnol. Bioeng. 2000, 70, 370-380.

24. Oyekola, O.O.; van Hille, R.P.; Harrison, S.T. Study of anaerobic lactate metabolism under biosulfidogenic conditions. Water Res. 2009, 43, 3345-3354.

25. APHA. Standard Methods for the Examination of Water and Wastewater; American Public Health Association: Washington, DC, USA, 1998.

26. Leloup, J.; Loy, A.; Knab, N.J.; Borowski, C.; Wagner, M.; Jorgensen, B.B. Diversity and abundance of sulfate-reducing microorganisms in the sulfate and methane zones of a marine sediment, Black Sea. Environ. Microbiol. 2007, 9, 131-142.

27. Klein, M.; Friedrich, M.; Roger, A.J.; Hugenholtz, P.; Fishbain, S.; Abicht, H.; Blackall, L.L.; Stahl, D.A.; Wagner, M. Multiple lateral transfers of dissimilatory sulfite reductase genes between major lineages of sulfate-reducing prokaryotes. J. Bacteriol. 2001, 183, 6028-6035.

(C) 2015 by the authors; licensee MDPI, Basel, Switzerland. This article is an open access article distributed under the terms and conditions of the Creative Commons Attribution license (http://creativecommons.org/licenses/by/4.0/). 